\title{
Sex ratio of infants born through in vitro fertilization and embryo transfer: Results of a single-institution study and literature review
}

\author{
Chinatsu Nagata ${ }^{1}$, Keiko Mekaru ${ }^{1}$, Keiya Gibo ${ }^{1}$, Rie Nakamura ${ }^{1}$, Sugiko Oishi ${ }^{1}$, Maho Miyagi ${ }^{1}$, Kozue Akamine ${ }^{1}$, \\ Yoichi Aoki ${ }^{1}$
}

${ }^{1}$ Department of Obstetrics and Gynecology, Graduate School of Medicine, University of the Ryukyus, 207 Uehara, Nishihara, Okinawa 903-0215, Japan

\begin{abstract}
Objective: The possible effects of Assisted Reproductive Technology (ART) on sex ratio at birth are extremely significant. This study aimed to determine whether ART affects the sex ratio of infants born through in vitro fertilization and embryo transfer (IVF-ET).

Materials and Methods: We ran this retrospective study on 290 singleton infants born following IVF-ET from February 2014 to August 2018 at a single institution. We compared the sex ratios of these infants with respect to insemination versus intracytoplasmic sperm injection (ICSI), early-cleavage embryo versus blastocyst transfer, fresh versus frozen-thawed embryo transfer and normal sperm versus asthenospermia.

Results: There were no significant differences in the sex ratio with respect to the fertilization method, transfer time, fresh embryo or frozen-thawed embryo transfer. In addition, the multiple logistic regression analysis revealed that these factors did not significantly affect the sex ratio.

Conclusions: Our study indicated that the differences in the fertilization method transfer time and sperm motility rate did not affect the sex ratio of IVF live births. However, with increasing numbers of ICSI and blastocyst transfer cycles, factors possibly affecting the sex ratio need to be further investigated.
\end{abstract}

Keywords: Fertility and assisted reproduction, Sex ratio, Intracytoplasmic sperm injection, Implantation, In vitro fertilization and embryo transfer, Insemination

\section{INTRODUCTION}

The Japanese Society of Obstetrics and Gynecology's ART registry system reported the total number of ART treatment cycles in 2017 to be 448,210 , resulting in 56,617 live births (Ishihara et al. 2020). In Japan, 1 in every 16.7 infants is conceived through ART. Both the number of treatment cycles and the number of infants born through ART have been increasing. In 2017, 4,826 live births involved ICSI, and the cumulative number of live births involving ICSI was 112,620 .

According to the 2017 Comprehensive Report of Vital Statistics released by the Ministry of Health, Labor and Welfare (2018), the total number of live births in Japan was 946,065 . The distribution by sex was 484,449 males and 461,616 females, for a sex ratio at birth (the ratio of males to females) of 1.05 . There are multiple reports that fewer male infants are born following ICSI than with natural pregnancy and insemination (Maalouf et al., 2014; Hentemann et al. 2009; Dean et al. 2010; Tarin et al. 2014; Arikawa et al. 2016). It has also been reported that the male birth rate increases if a blastocyst transfer is performed (Maalouf et al., 2017; Dean et al. 2010; Tarin et al. 2014). Therefore, the fertilization method and the stage at transfer may affect the sex ratio. Moreover, as a technician selects the sperm used in ICSI, concerns have been raised over the effects of human intervention on the sex ratio. If the use of ART continues to increase, the sex ratio may be affected.

This study aimed to determine whether the differences in the fertilization method, time of transfer, sperm motility rate or different ICSI technicians at our hospital affected the sex ratio of live births via in vitro fertilization.

\section{MATERIALS AND METHODS \\ Study design and participants}

This retrospective study reviewed 290 singleton infants born following in vitro fertilization and embryo transfer (IVF-ET) from February 2014 to August 2018 at the University of the Ryukyus Hospital (Okinawa, Japan). This study was carried out according to the guidelines of the Declaration of Helsinki. The ethical review board of the University of Ryukyus (Okinawa, Japan) approved the study protocol, and all patients provided informed consent prior to their inclusion in the study.

\section{IVF protocol}

In preparation for IVF/ICSI, we used either a long or short gonadotropin-releasing hormone agonist protocol or a gonadotropin-releasing hormone antagonist protocol for controlled ovarian stimulation. Protocol selection was based on the patient's ovarian function. Oocyte pick-up was conducted when the dominant follicles were $\geq 18 \mathrm{~mm}$ in diameter using transvaginal ultrasound. Fertilization was performed using IVF or ICSI. We collected the sperm via the swim-up method.

The embryos were cultured at $37.0^{\circ} \mathrm{C}$ using a supply gas concentration of $5.0 \% \mathrm{CO}_{2}, 5.0 \% \mathrm{O}_{2}$ and $90.0 \% \mathrm{~N}_{2}$ in a water-jacketed or drawer-type incubator. Fertilization was confirmed after 18-20h. Normal fertilization was confirmed by observing a male or female pronucleus.

The embryos were evaluated using the Veeck's classification (Veeck, 1988) system for early-cleavage embryos and the Gardner's classification system (Gardner et al. 2000) for blastocysts. We defined asthenospermia as total sperm motility $<40 \%$ and normal sperm as total sperm motility $>40 \%$ in undiluted semen according to the World Health Organization (WHO) classification of subfertility (WHO, 2010).

The embryos were frozen and thawed in accordance with the protocols of the Vitrification Kit (Kitazato Corporation, Shizuoka, Japan) or the Cryotop Safety Kit (Kitazato Corporation, Shizuoka, Japan) manufacturer. All embryo transfers were performed using transabdominal ultrasound during either a hormone replacement cycle or a natural cycle. 


\section{Outcome measures}

The sex ratios of the IVF products were compared with respect to insemination versus ICSI, early-cleavage versus blastocyst transfer, fresh versus frozen-thawed embryo transfer and normal sperm versus asthenospermia in undiluted semen. Additionally, the sex ratio of live births involving ICSI was determined for each embryologist ( $A$ or B).

\section{Statistics}

Either the $\mathrm{x} 2$ test or logistic regression analysis was applied for statistical purposes. A $p$-value $<0.05$ was considered statistically significant. We used the JMP software (SAS Institute, Inc., Cary, NC, USA) for the statistical analyses.

\section{RESULTS}

The mean maternal age of the subjects was $35.4 \pm 4.0$ years. We had 290 singleton infants born following IVF-ET at our hospital between February 2014 and August 2018. Of these, $136(46.9 \%)$ live-born infants were conceived using insemination, whereas $154(53.1 \%)$ were conceived using ICSI. In addition, 76 (26.2\%) live-born infants were conceived via early embryo transfer, whereas $214(73.8 \%)$ were conceived via blastocyst transfer. Forty-five (15.5\%) live-born infants were conceived via fresh embryo transfer, whereas $245(84.5 \%)$ were conceived via frozen-thawed embryo transfer.

Table 1 presents the sex ratio $(X Y / X X)$ of the infants with respect to the fertilization method, transfer time and fresh versus frozen-thawed embryo transfer. There were no significant difference in sex ratio with respect to the fertilization method, transfer time or fresh versus frozenthawed embryo transfer.

Table 2 presents the sex ratio with regard to differences in pre-treatment sperm motility rate, and each ICSI technician. There were no significant differences in the sex ratio about sperm motility rate or between individual technicians. We ran a logistic regression analysis for the data regarding the fertilization method, transfer time, fresh versus frozen-thawed embryos, maternal age, and number of good-quality embryos transferred or sperm motility rate. None of these factors affected the sex ratio.

\section{DISCUSSION}

Table 3 depicts a review of a number of previous studies reporting the sex ratio of infants born by assistedconception techniques. Although it has been reported that fewer male live-born infants are conceived via ICSI than through natural pregnancy and insemination (Maalouf et al. ,2017; Hentemann et al., 2009; Dean et al. 2010; Tarin et al. 2014, Arikawa et al. 2016; Luke et al. 2009) we did not see significant differences in the sex ratio with regards to the fertilization method in our study population. In this study, blastocyst transfer cycles were performed after ICSI three times more frequently than early embryo transfer cycles, $75.3 \%$ (116/154 cycles) versus $24.7 \%$ (38/154 cycles), respectively. It has been reported that there were higher male infant birth rates following blastocyst transfer cycles than early embryo transfer cycles (Maalouf et al., 2014), suggesting the lack of a significant difference in sex ratio between the two transfer techniques in this study. The fact that this blastocyst transfer cycle is frequently performed is considered a possibility that there is no significant difference in sex ratio in our study population.

Several reports have investigated the factors associated with a higher male infant birth rate found in blastocyst transfer cycles (Maalouf et al. 2014; Hentemann et al., 2009; Dean et al. 2010). Genes controlling glucose uptake, metabolism and antioxidant enzymes are located on the X chromosome (Gutiérrez-Adán et al. 2000; Pérez-Crespo et al., 2005). A study examining cow and mice embryos reported that the expression of gene coding for the enzymes glucose-6-phosphate dehydrogenase (G6PD) and hypoxanthine phosphoribosyl transferase, both involved in energy metabolism, is higher in female than in male embryos (Gutiérrez-Adán et al. 2000; Pérez-Crespo et al., 2005). Human embryos have similar gene expression patterns. Although female embryos have higher energy metabolism, they may also be under oxidative stress

Table 1. Sex ratio $(X Y / X X)$ by fertilization method, transfer time and fresh or frozen-thawed embryo transfer.

\begin{tabular}{|c|c|c|c|}
\hline Method of fertilization & $\begin{array}{l}\text { Transfer time } \\
\text { Fresh/frozen-thawed embryo } \\
\text { transfer }\end{array}$ & Sex ratio $(X Y / X X)$ & $p$ \\
\hline \multirow{2}{*}{$\operatorname{IVF}(n=136)$} & $\begin{array}{l}\text { Early embryo }(n=38) \\
\text { Blastocyst }(n=98)\end{array}$ & $\begin{array}{l}1.53(23 / 15) \\
1.13(52 / 46)\end{array}$ & 0.43 \\
\hline & $\begin{array}{l}\text { Fresh embryo }(n=30) \\
\text { Frozen-thawed embryo }(n=106)\end{array}$ & $\begin{array}{l}1.31(17 / 13) \\
1.21(58 / 48) \\
\end{array}$ & 0.85 \\
\hline \multirow{3}{*}{ ICSI $(n=154)$} & $\begin{array}{l}\text { Early embryo }(n=38) \\
\text { Blastocyst }(n=116)\end{array}$ & $\begin{array}{l}1.24(21 / 17) \\
1.23(64 / 52) \\
\end{array}$ & 0.99 \\
\hline & Fresh embryo $(n=15)$ & $0.50(5 / 10)$ & \multirow{2}{*}{0.07} \\
\hline & Frozen-thawed embryo $(n=139)$ & $1.36(80 / 59)$ & \\
\hline
\end{tabular}

Table 2. Sex ratio by pre-treatment sperm motility rate and intracytoplasmic sperm injection (ICSI) technician.

\begin{tabular}{|c|c|c|c|}
\hline $\begin{array}{l}\text { Method of fertilization } \\
\text { ICSI technician }\end{array}$ & $\begin{array}{l}\text { Sperm motility } \\
\text { ICSI technician }\end{array}$ & Sex ratio $(X Y / X X)$ & $p$ \\
\hline $\operatorname{IVF}(n=136)$ & $\begin{array}{l}\text { Normal sperm }(n=122) \\
\text { Asthenospermia }(n=13)\end{array}$ & $\begin{array}{c}1.12(65 / 58) \\
3.33(10 / 3)\end{array}$ & 0.10 \\
\hline ICSI $(n=140)$ & $\begin{array}{l}\text { Normal sperm }(n=92) \\
\text { Asthenospermia }(n=48)\end{array}$ & $\begin{array}{l}1.14(49 / 43) \\
1.40(28 / 20)\end{array}$ & 0.57 \\
\hline ICSI technician & $\begin{array}{l}\text { Technician A }(n=50) \\
\text { Technician B }(n=33)\end{array}$ & $\begin{array}{l}1.08(26 / 24) \\
2.00(22 / 11)\end{array}$ & 0.19 \\
\hline
\end{tabular}




\begin{tabular}{|c|c|c|c|c|}
\hline Author (year) & Country & $\begin{array}{c}\text { Number of } \\
\text { births }\end{array}$ & $\begin{array}{c}\text { ART } \\
\text { treatment }\end{array}$ & $\begin{array}{c}\text { Sex ratio } \\
\text { (\% of male) }\end{array}$ \\
\hline $\begin{array}{l}\text { Hentemann et al. } \\
\text { (2009) }\end{array}$ & $\begin{array}{l}\text { Single institution } \\
\text { (Norway) }\end{array}$ & 420 & $\begin{array}{c}\text { ICSI } \\
\text { Blastocyst } \\
\text { (IVF) }\end{array}$ & $\begin{array}{l}0.69 \\
1.17\end{array}$ \\
\hline Luke et al. (2009) & $\begin{array}{l}\text { Society for Assisted } \\
\text { Reproductive } \\
\text { Technology National } \\
\text { Database (USA) }\end{array}$ & 15,164 & $\begin{array}{l}\text { Blastocyst } \\
\text { (ICSI) }\end{array}$ & 0.98 \\
\hline Dean et al. (2010) & $\begin{array}{l}\text { Fertility clinics in } \\
\text { Australia and New } \\
\text { Zealand } \\
\end{array}$ & 13,368 & $\begin{array}{c}\text { IVF } \\
\text { Blastocyst } \\
\text { (IVF) }\end{array}$ & $\begin{array}{l}1.13 \\
1.27\end{array}$ \\
\hline Maalouf et al. (2014) & United Kingdom & 106,066 & $\begin{array}{c}\text { IVF } \\
\text { ICSI } \\
\text { Blastocyst } \\
(\mathrm{IVF}+\mathrm{ICSI})\end{array}$ & $\begin{array}{l}1.08 \\
0.96 \\
1.27\end{array}$ \\
\hline Arikawa et al. (2016) & Japan & 27,158 & $\begin{array}{l}\text { IVF } \\
\text { ICSI }\end{array}$ & $\begin{array}{l}1.13 \\
0.92\end{array}$ \\
\hline Current study & $\begin{array}{c}\text { Ryukyu University } \\
\text { Hospital }\end{array}$ & 290 & & $\begin{array}{c}\text { No significant } \\
\text { differences in sex ratio }\end{array}$ \\
\hline
\end{tabular}

due to this more active metabolism, making them more liable for growth retardation and poor quality than male embryos. This has been demonstrated by the fact that there is less growth retardation in female mice embryos cultured with G6PD inhibition (Pérez-Crespo et al., 2005). However, it has been reported that in both human and cow embryos, glucose metabolism in the male embryo is significantly higher than that in the female embryo from the morula to blastocyst stages (Tiffin et al. 1991; Jiménez et al., 2003). As such, male embryos may develop into blastocysts earlier than female embryos. Based on these findings, it has been suggested that male embryos develop into embryos that are more robust because they are less susceptible to oxidative stress. Moreover, male embryos develop into blastocysts earlier than female embryos because of the higher glucose metabolism in male embryos from the morula stage to the blastocyst stage. This means that more male blastocysts may be selected for fresh embryo transfer or during cryopreservation.

It has been reported that, in embryos fertilized with morphologically good sperm, more female embryos are selected for sperm injection. This is believed to be because sperm are selected under high magnification and that with a higher ratio of morphologically good and normal sperm, the percentage of sperm carrying an $X$ chromosome is higher (Setti et al. 2012). Since ICSI involves artificial selection of good-quality sperm, it is possible that sperm carrying the $\mathrm{X}$ chromosome are preferentially selected, thus affecting the sex ratio.

Sperm motility rate may be associated with sex ratio during insemination. It has been reported that the male birth rate is significantly lower in groups with low-motility sperm (Arikawa et al. 2016). However, the male birth rate was lower from pre-treatment sperm motility rate for either insemination or ICSI at our hospital.

The culture environment also seems affect sex ratio. Compared with X-chromosome sperm, Y-chromosome sperm are more vulnerable to temperature changes and culture duration, and the expression of gene coding for proteins involved in apoptosis is higher in Y-chromosome sperm (You et al. 2017). In an experiment comparing blastocyst transfer in mice embryos cultured at $37^{\circ} \mathrm{C}$ or $41^{\circ} \mathrm{C}$, the male to female sex ratio of the group cultured at $41^{\circ} \mathrm{C}$ was found to be lower than the ones cultured at $37{ }^{\circ} \mathrm{C}$ (Pérez-Crespo et al., 2005). Because all of the embryos in our study were cultured in the same environment, culture environment was unlikely to have affected the sex ratio.
The possibility of sex selection in the endometrium was also considered, but another study failed to demonstrate sexual selection in mice endometrium, making this unlikely (Jiménez et al., 2003). Therefore, the three factors that appear to affect sex ratio include the speed at which the embryo develops, the rate of embryo metabolism due to the sex of the embryo and embryo selection during transfer and cryopreservation.

\section{CONCLUSION}

Our study demonstrates that differences in the fertilization method, transfer time and sperm motility rate, and differences between individual ICSI technicians do not affect the sex ratio in IVF live births. However, with the increasing numbers of ICSI cycles and blastocyst transfer cycles being performed, additional factors that may affect the sex ratio need to be further investigated.

\section{ACKNOWLEDGMENTS}

The authors would like to thank Enago (www.enago.jp) for an English language review.

\section{Data Availability}

The data used to support the findings of this study are available from the corresponding author upon request.

\section{CONFLICT OF INTEREST}

The authors declare that there is no conflict of interest regarding the publication of this paper.

\author{
Corresponding Author: \\ Keiko Mekaru \\ Department of Obstetrics and Gynecology \\ Graduate School of Medicine \\ University of the Ryukyus \\ Nishihara, Okinawa, Japan \\ E-mail: f041252@eve.u-ryukyu.ac.jp
}

\section{REFERENCES}

Arikawa M, Jwa SC, Kuwahara A, Irahara M, Saito H. Effect of semen quality on human sex ratio in in vitro fertilization and intracytoplasmic sperm injection: an analysis of 27,158 singleton infants born after fresh single-embryo transfer. Fertil Steril. 2016;105:897-904. PMID: 26738748 DOI: $10.1016 /$ j.fertnstert.2015.12.009 
Dean JH, Chapman MG, Sullivan EA. The effect on human sex ratio at birth by assisted reproductive technology (ART) procedures--an assessment of babies born following single embryo transfers, Australia and New Zealand, 20022006. BJOG. 2010;117:1628-34. PMID: 20875033 DOI: 10.1111/j.1471-0528.2010.02731.x

Gutiérrez-Adán A, Oter M, Martínez-Madrid B, Pintado B, De La Fuente J. Differential expression of two genes located on the X chromosome between male and female in vitroproduced bovine embryos at the blastocyst stage. Mol Reprod Dev. 2000;55:146-51. PMID: 10618653 DOI: 10.1002/ (SICI)1098-2795(200002)55:2<146: :AIDMRD3>3.0.CO;2-F

Gardner DK, Lane M, Stevens J, Schlenker T, Schoolcraft WB. Blastocyst score affects implantation and pregnancy outcome: towards a single blastocyst transfer. Fertil Steril. 2000;73:11558. PMID: 10856474 DOI: 10.1016/S0015-0282(00)00518-5

Hentemann MA, Briskemyr S, Bertheussen K. Blastocyst transfer and gender: IVF versus ICSI. J Assist Reprod Genet. 2009;26:433-6. PMID: 19731005 DOI: 10.1007/ s10815-009-9337-3

Jiménez $A$, Fernández R, Madrid-Bury $N$, Moreira PN, Borque C, Pintado B, Gutiérrez-Adán A. Experimental demonstration that pre- and post-conceptional mechanisms influence sex ratio in mouse embryos. Mol Reprod Dev. 2003;66:162-5. PMID: 12950103 DOI: $10.1002 / \mathrm{mrd} .10345$

Luke B, Brown MB, Grainger DA, Baker VL, Ginsburg E, Stern JE; Society for Assisted Reproductive Technology Writing Group. The sex ratio of singleton offspring in assistedconception pregnancies. Fertil Steril. 2009;92:1579-85. PMID: 18950756 DOI: 10.1016/j.fertnstert.2008.08.107

Maalouf WE, Mincheva MN, Campbell BK, Hardy IC. Effects of assisted reproductive technologies on human sex ratio at birth. Fertil Steril. 2014;101:1321-5. PMID: 24602756 DOI: $10.1016 /$ j.fertnstert.2014.01.041

Ministry of Health, Labour and Welfare (JPN). Comprehensive report of vital statistics for 2017. Updated 2018. Tokyo: Ministry of Health; 2018. Available at: http:// www.mhlw.go.jp/toukei/saikin/hw/jinkou/kakutei15/ index.html. Accessed:07/05/2020.
Pérez-Crespo M, Ramírez MA, Fernández-González R, Rizos $D$, Lonergan $P$, Pintado $B$, Gutiérrez-Adán A. Differential sensitivity of male and female mouse embryos to oxidative induced heat-stress is mediated by glucose-6phosphate dehydrogenase gene expression. Mol Reprod Dev. 2005;72:502-10. PMID: 16149081 DOI: 10.1002/ mrd.20366

Ishihara O, Jwa SC, Kuwahara A, Katagiri Y, Kuwabara Y,Hamatani T, Harada M, Ichikawa T. Assisted reproductive technology in Japan: a summary report for 2017 by the Ethics Committee of the Japan Society of Obstetrics and Gynecology. Reprod Med Biol. 2019;19:3-12. PMID: 31956280 DOI: $10.1002 / \mathrm{rmb} 2.12307$

Setti AS, Figueira RC, Braga DP, Iaconelli Junior A, Borges Junior E. Gender incidence of intracytoplasmic morphologically selected sperm injection-derived embryos: a prospective randomized study. Reprod Biomed Online. 2012;24:420-3. PMID: 22377154 DOI: 10.1016/j. rbmo.2012.01.007

Tarín JJ, García-Pérez MA, Hermenegildo C, Cano A. Changes in sex ratio from fertilization to birth in assisted-reproductive-treatment cycles. Reprod Biol Endocrinol.2014;12:56. PMID: 24957129 DOI: 10.1186/1477-7827-12-56

Tiffin GJ, Rieger D, Betteridge KJ, Yadav BR, King WA. Glucose and glutamine metabolism in pre-attachment cattle embryos in relation to sex and stage of development. J Reprod Fertil. 1991;93:125-32. PMID: 1920281 DOI: $10.1530 /$ jrf.0.0930125

Veeck LL. Oocyte assessment and biological performance. Ann N Y Acad Sci. 1988;541:259-74. PMID: 3195909 DOI: 10.1111/j.1749-6632.1988.tb22263.x

World Health Organization (WHO). WHO laboratory manual for the examination and processing of human semen. 5th ed. Geneva: WHO; 2010. You YA, Kwon WS, Rahman MS, Park YJ, Kim YJ, Pang MG. Sex chromosome-dependent differential viability of human spermatozoa during prolonged incubation. Hum Reprod. 2017;32:1183-91. PMID: 28430968 DOI: 10.1093/humrep/dex080 